\title{
Oxigênio Medicinal e a sua importância durante a pandemia de COVID-19: uma visão preliminar sobre o mercado de oxigênio medicinal do Brasil
}

\author{
Medicinal oxygen and its importance during the COVID-19 pandemic: a preliminary view on the \\ Brazilian medical oxygen market
}

\section{Lauanne Steter dos Santos Rocha*, João Victor Rodrigues Rocha, Gabriel Alves de Souza Gonçalves, Moisés Teles Madureira}

Como citar esse artigo. Rocha, LSS; Rocha, JVR; Gonçalves, GAS; Madureira, MT. Oxigênio Medicinal e a sua importância durante a pandemia de COVID-19: uma visão preliminar sobre o mercado de oxigênio medicinal do Brasil.. Revista Teccen. 2021 Jul./Dez.; 14 (2): 07-16

\section{Resumo}

O gás oxigênio, por suas variadas aplicações industriais, é um produto de fundamental importância para sociedade. Uma de suas aplicações inclui o uso como gás medicinal que possui rígidas especificações de qualidade comparativamente às demais aplicações industriais. Durante a pandemia de COVID-19 sua importância tornou-se ainda mais evidente e a crescente demanda levantou questionamentos quanto a capacidade de suprimento do mercado consumidor. Nesse sentido, o objetivo deste trabalho consistiu em apresentar uma visão panorâmica do mercado consumidor de oxigênio medicinal do Brasil, com dados disponibilizados por órgãos governamentais, bem como realizar um estudo de caso referente ao aumento do consumo no Hospital Universitário de Vassouras (HUV), que no decurso da calamidade de saúde pública, também percebeu os impactos de um aumento significativo da demanda pelo produto. Em complemento à fundamentação do trabalho, expôs-se uma revisão da literatura sobre o processo de obtenção do gás oxigênio de alta pureza e foram reportadas algumas medidas implementadas pela Agência Nacional de Vigilância Sanitária brasileira que tiveram o intuito de proporcionar ganho de eficiência produtiva por parte das empresas fornecedoras. Dentre os resultados obtidos, constatou-se que nos anos de 2020 e 2021, período de grande disseminação do vírus, o HUV teve um consumo de oxigênio da ordem de 19,68\% superior ao consumo do ano de 2019 e 10,91\% maior que o consumido em 2020 , respectivamente. Destaca-se ainda que o aumento de $10,91 \%$ se refere apenas ao período entre janeiro e agosto de 2021 . No contexto da crise gerada pela COVID-19, uma das lições aprendidas pode indicar a necessidade das organizações se prepararem melhor para a possibilidade de enfrentar situações adversas. Tal possibilidade motivou o exercício de um processo de gestão de riscos, consistindo em uma análise qualitativa consolidada de 4 itens de riscos, como forma de boa prática, permitindo a geração de um plano de resposta, visando o contingenciamento de eventos adversos futuros. Palavras-Chave: Gases industriais; Oxigênio medicinal; Suprimento de oxigênio medicinal.

\begin{abstract}
Oxygen gas, due to its many industrial applications, is a product of fundamental importance to society. One of its applications includes use as a medical gas that has strict quality specifications compared to other industrial applications. During the pandemic of COVID-19 its importance became even more evident and the growing demand raised questions about the supply capacity of the consumer market. In this sense, the objective of this work was to present a panoramic view of the medical oxygen consumer market in Brazil, with data made available by government agencies, as well as to conduct a case study regarding the increased consumption at the University Hospital of Vassouras (HUV), which, during the course of the public health calamity, also perceived the impacts of a significant increase in demand for the product. As a complement to the work, a literature review on the process of obtaining high purity oxygen gas was presented, and some measures implemented by the Brazilian National Health Surveillance Agency were reported, aiming to provide gains in production efficiency by the supplying companies. Among the results obtained, it was found that in the years 2020 and 2021, period of great dissemination of the virus, the HUV had an oxygen consumption in the order of $19.68 \%$ higher than the consumption in 2019 and $10.91 \%$ higher than the consumption in 2020, respectively. It is also noteworthy that the $10.91 \%$ increase refers only to the period between January and August 2021 . In the context of the crisis generated by COVID-19, one of the lessons learned may indicate the need for organizations to better prepare for the possibility of facing adverse situations. This possibility motivated the exercise of a risk management process, consisting of a consolidated qualitative analysis of 4 risk items, as a form of good practice, allowing the generation of a response plan, aiming at the contingency of future adverse events.

Keywords: Industrial gases; Medicinal oxygen; Supply of medicinal oxygen.
\end{abstract}

Afiliação dos autores:

${ }^{1}$ Universidade de Vassouras, Curso de Engenharia Química, Vassouras, RJ, Brasil.

* Email para correspondência: lauannesteter@gmail.com 


\section{Introdução}

Os gases estão presentes em diversos segmentos da indústria tais como a área hospitalar, alimentícia, têxtil, combustíveis, siderurgia e outras. Segundo a ABIQUIM (Associação Brasileira da Indústria Química, 2020) a participação da indústria química brasileira, no qual o setor de gases está inserido, em 2019 compreendeu 2,3\% sobre o total do PIB no referido ano. Em 2020, estimou-se que o faturamento líquido do setor de gases industriais tenha sido de US\$2,0 bilhões de dólares. Dentre os principais produtos desse setor encontram-se o Gás Carbônico, o Nitrogênio, o Oxigênio, o Argônio, o Acetileno, o Hidrogênio e o Hélio (MELLO, et al., 2007)

$\mathrm{O}$ setor de gases industriais opera em um mercado darwiniano, no qual os princípios da seleção natural levam à sobrevivência apenas das empresas mais ajustadas às necessidades do cliente (PACHIONE, 2003).

De acordo com Shreve \& Brink (1997) o gás oxigênio é produzido quase que exclusivamente pela liquefação e posterior retificação do ar em usinas muito eficientes, termicamente bem isoladas e compactas. As usinas variam em porte, podendo produzir menos de 25 toneladas em pequenas unidades ou plantas industriais com produção diária superior a 1000 toneladas.

Considerado como uma substância essencial para a manutenção da vida, o gás oxigênio tem sua notoriedade evidenciada pelo atual contexto em que o mundo enfrenta a maior pandemia de sua história recente.

Tendo seu surgimento identificado pela primeira vez na cidade de Wuhan na China no ano de 2019, o vírus denominado de SARS-CoV-2 pertence a uma grande família de vírus. A disseminação e transmissão da doença COVID-19 ocorreu de forma rápida e em caráter mundial causando dentre seus principais sintomas a infecção respiratória. Especificamente no dia 26 de fevereiro de 2020, o Brasil relatou a confirmação do primeiro caso de coronavírus localizado na cidade de São Paulo (Ministério da Saúde, 2020a).

Estima-se que entre $10 \%$ e $15 \%$ dos pacientes com COVID-19 necessitam de internação em terapia intensiva por insuficiência respiratória aguda determinada por pneumonia viral. Tais pacientes geralmente apresentam aumento da frequência respiratória e hipoxemia (Ministério da Saúde, 2021).

Assim sendo, o suprimento de oxigênio medicinal caracterizado como item essencial pela Organização Mundial de Saúde (OMS, 2019) tem sido amplamente utilizado nos hospitais durante a pandemia de COVID19 como um método de oxigenação complementar dos pacientes infectados. A demanda pelo produto no Brasil esteve associada ao aumento dos casos, e gerou preocupações a respeito da capacidade produtiva e de fornecimento ao mercado consumidor.

Nesse sentido, os objetivos deste trabalho consistem em trazer ao conhecimento do público interessado uma revisão de literatura sobre o processo de produção do oxigênio voltado para uso medicinal, o aumento da demanda do produto no Hospital Universitário de Vassouras e a alternativa encontrada pela indústria para suprir a demanda em caráter emergencial em estados em situação crítica de abastecimento. Em virtude dos acontecimentos decorridos durante a pandemia, o presente trabalho apresenta uma proposta de gestão de riscos, como forma de relatar lições aprendidas durante a crise de saúde e apontar planos de resposta para ao menos mitigar a ocorrência futura de problemas com o mesmo nível de gravidade.

\section{Materiais e Métodos}

Realizou-se uma revisão bibliográfica através de dados secundários extraídos de artigos científicos, monografias e sites relacionados ao tema abordado através da base de dados do Google Acadêmico, Agência Nacional de Vigilância Sanitária (ANVISA), Instituto Brasileiro de Geografia e Estatística (IBGE) e Ministério da Saúde (MS).

Foram obtidas informações sobre o consumo de oxigênio medicinal no Hospital Universitário (HUV) localizado na cidade de Vassouras no período de prépandemia do ano de 2019 e no período de disseminação do vírus no decurso dos anos de 2020 e 2021 no Brasil.

\section{Processo de obtenção do gás oxigênio}

Existem três principais técnicas de separação do ar, sendo elas: (1) Destilação, (2) Adsorção e (3) Membranas, dentre as quais, a técnica de destilação (1) é a mais eficiente produzindo em larga escala gases de purezas superiores a 99\%. A adsorção (2) tem capacidade de produzir purezas de oxigênio de até $95 \%$, entretanto, essa técnica apresenta altos custos de produção e requer adsorventes com limites de tamanhos. O método por membranas (3) fornece produtos com baixa pureza (95 a 99\%). Outros métodos de técnicas de separação de ar são adsorção de oscilação de pressão e adsorção de oscilação de pressão de vácuo que são usados para separar um único componente do ar atmosférico. Mas oxigênio, nitrogênio e argônio de alta pureza são produzidos por destilação criogênica (NAIK,2015).

O processo chamado de destilação criogênica consiste em linhas gerais na liquefação do ar para separação dos gases através dos pontos de ebulição de cada componente (DUARTE,2017).

Determina-se que o processo de obtenção de gases medicinais para distribuição e comercialização sejam 
exclusivamente por meio do processo de liquefação criogênica, atendendo a pureza mínima de $99,0 \% \mathrm{v} / \mathrm{v}$ (ANVISA,2021a).

Os gases medicinais são moléculas gasosas destinadas a entrar em contato direto com o organismo humano, sendo utilizadas como opções terapêuticas para diversas doenças (VIEIRA, et al., REDIGIERI, 2013).

No processo de liquefação criogênica utiliza-se o ar como fonte de oxigênio. $\mathrm{O}$ ar é uma mistura de diversas substâncias, seus principais componentes e seus respectivos volumes percentuais são: Nitrogênio (78,084\%), Oxigênio $(20,946 \%)$, Dióxido de carbono $(0,02-0,04 \%)$ e outros gases $(0,9365144 \%)$ (SHREVE \& BRINK, 1997).

A maior parte do oxigênio produzido é de elevada pureza $(99,5 \%)$. A produção de oxigênio de baixa pureza tem sua concentração na faixa de 95 a $99 \%$, onde a maioria dos contaminantes são o argônio juntamente com traços de gases raros, hidrocarbonetos e dióxido de carbono (SHREVE \& BRINK, 1997).

A produção de oxigênio gasoso de elevada pureza a partir do ar, mediante processo criogênico dá-se pelas seguintes etapas apresentadas no diagrama ilustrado na figura 1 .

\section{Resultados e Discussão}

\section{Mercado de consumo}

O setor de gases compreende principalmente fabricantes de gases orgânicos e inorgânicos industriais. De acordo com a jurisprudência do Conselho Administrativo de Defesa Econômica (2018), o termo "gases industriais" contempla em seu segmento os gases medicinais, que usualmente são produzidos na mesma planta. A diferença de aplicação para fim industrial e para medicinal é o tempo adicional que o último leva para ser testado, a lavagem necessária do equipamento de armazenagem para retirada de impurezas que porventura possam prejudicar o paciente e o grau de pureza de acordo sua destinação.

De acordo com o IBGE (2020), entre os anos de 2014 e 2018 foram produzidos 29.424 .832 mil metros cúbicos de oxigênio no Brasil. A figura 2 exibe a produção brasileira do gás oxigênio entre os referidos anos. Observa-se na figura 2 que, o mercado de gás oxigênio cresceu a uma taxa de 7,54\%, sofrendo leves variações na produção ao longo dos anos de 2015 e 2016.

Em 2018, o mercado de gás industrial no Brasil produziu aproximadamente 6,4 milhões mil metros cúbicos de oxigênio, totalizando o valor de $\mathrm{R} \$$ 2.100.181,00 milhões de mil reais. No mesmo período, foram vendidos $90,35 \%$ do volume total produzido,

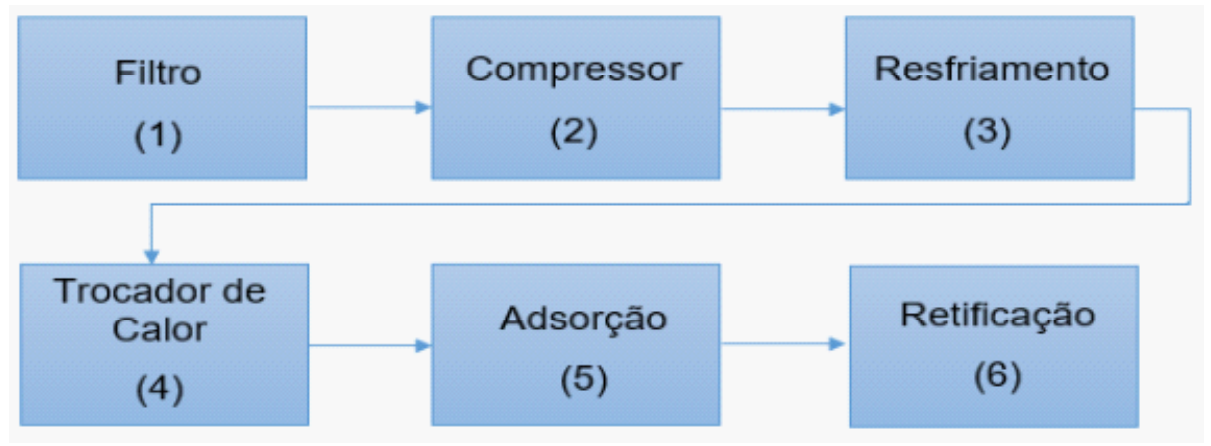

Figura 1. Diagrama de blocos da obtenção do oxigênio de alta pureza através do processo criogênico.

O processo ilustrado na figura 1 pode ser melhor entendido por meio do suporte de informações detalhadas, conforme os blocos identificados:

(1) Remoção de impurezas suspensas;

(2) Compressão até 5,1 atm;

(3) Resfriamento para ocorrer a separação da água líquida;

(4) Troca de calor para retirada da umidade e dióxido de carbono presente no ar que irão se depositar sobre as paredes do trocador de calor. Ao final da troca térmica o ar está completamente seco e livre de mais de $99 \%$ de dióxido de carbono anteriormente presente;

(5) Adsorção em fase gasosa e a leito fixo para a remover o restante do dióxido de carbono e principalmente traços de hidrocarbonetos;

(6) Retificação composta por duas colunas de destilação com pratos que, através da diferença de volatilidade irá proporcionar a separação do Oxigênio e Nitrogênio. Logo, o Oxigênio de alta pureza estará depositado no estado líquido no fundo da coluna superior.

Fonte: Adaptado de Shreve \& Brink (1997). 


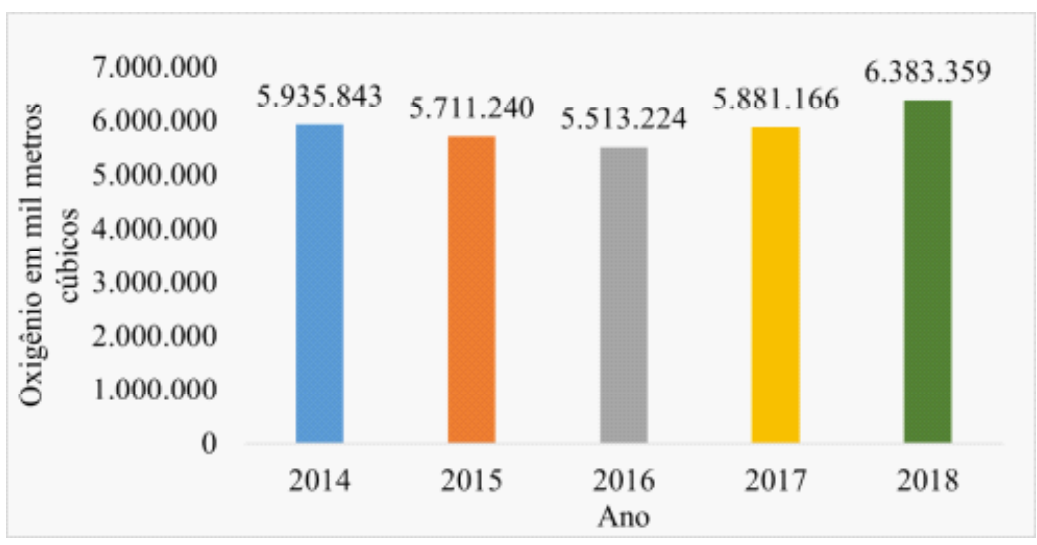

Figura 2. Gás oxigênio produzido no Brasil em mil metros cúbicos.

Fonte: IBGE (2020).

compreendendo 5.767.645 milhões de mil metros cúbicos de oxigênio (IBGE, 2020) .

\section{Crise do suprimento de oxigênio durante a pandemia}

Com a pandemia de COVID-19 observou-se um aumento significativo da demanda voltada para o gás com a finalidade de uso medicinal no Brasil. Devido a isso, o setor enfrentou desafios quanto a capacidade de suprir a demanda pelo produto, acarretada pela calamidade de saúde e fez-se necessário a adoção de medidas capazes de agrupar esforços quanto ao aumento da produção e consequente distribuição.

Com a expectativa de fornecer mais acesso ao produto em caráter emergencial à população, a ANVISA (2021b, 2021c) deliberou as seguintes resoluções:

- Resolução da Diretoria Colegiada 461/2021 autorizou temporariamente a produção e distribuição de oxigênio medicinal a $95 \%$ de pureza, com o objetivo de proporcionar o ganho de eficiência produtiva;

- Resolução da Diretoria Colegiada 482/2021 concedeu permissão para que se utilizassem cilindros de gases industriais para o enchimento de gás medicinal, sob a condição de que fossem atendidos todos os critérios das Boas Práticas de Fabricação (BPF) e desde que os cilindros fossem submetidos a purgas e inspeções internas para eliminar os riscos de contaminação cruzada.

Segundo ANVISA (2021d), as medidas implementadas foram capazes de aumentar de $5 \%$ a $200 \%$ a capacidade de produção e envase do oxigênio medicinal, fator que colaborou para que pudesse ser evitado o risco de desabastecimento do mercado.

Em complemento às Resoluções estabelecidas, foi publicado pela ANVISA (2021e) o Edital de Chamamento $\mathrm{n}^{\circ} 5 / 2021$ requerendo às empresas brasileiras (fabricantes, envasadoras e distribuidoras do gás medicinal, nas formas farmacêuticas gás e líquido) que informassem as quantidades de gás oxigênio presentes em seus estoques e os volumes comercializados.

Em resposta às informações fornecidas pelas empresas, a ANVISA (2021f) tornou público um Painel na internet disponibilizando os valores das vendas apuradas nas regiões geográficas do país. As figuras $3 \mathrm{e}$ 4 mostram as vendas do oxigênio medicinal envasado e não envasado no Brasil referentes ao período de março até agosto de 2021.

Conforme descriminado na figura 3, identificase que a Região Sudeste do Brasil comercializou $32.302 .948,03 \mathrm{~m}^{3}$ do gás oxigênio medicinal envasado em cilindros entre os meses de março a agosto de 2021, o que compreende aproximadamente $57,52 \%$ do total distribuído em todo o território nacional.

Já a figura 4, ainda referente à Região Sudeste, no mesmo período foram comercializados ao todo 127.232.108,45 m3 do oxigênio na sua forma farmacêutica líquida consistindo em $51,36 \%$ do total no território nacional.

Os fatores que contribuíram para a maior incidência de consumo desta região foram a sua população residente e o número de casos confirmados da doença COVID-19 superior a das demais regiões, conforme demonstrado na figura 5 .

\section{Impactos percebidos pelo Hospital Universitário de Vassouras (HUV) em função dos casos de COVID-19}

Localizado no interior do estado do Rio de 


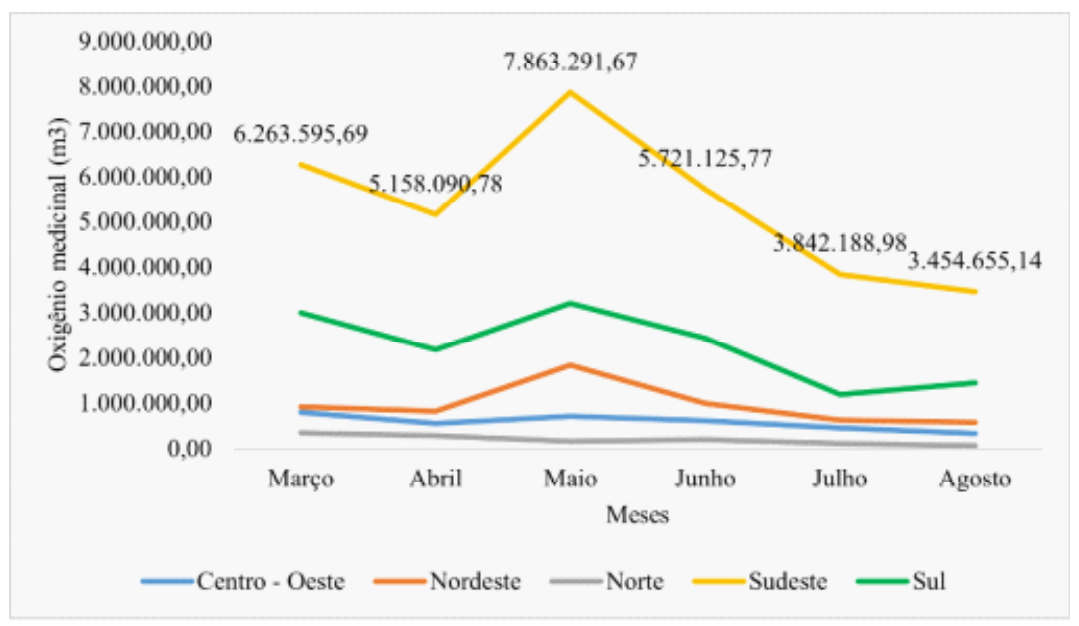

Figura 3. Venda de Oxigênio Medicinal Envasado em Cilindro no Brasil ( $\left.\mathrm{m}^{3}\right)$.

Fonte: Adaptado de ANVISA (2021f).

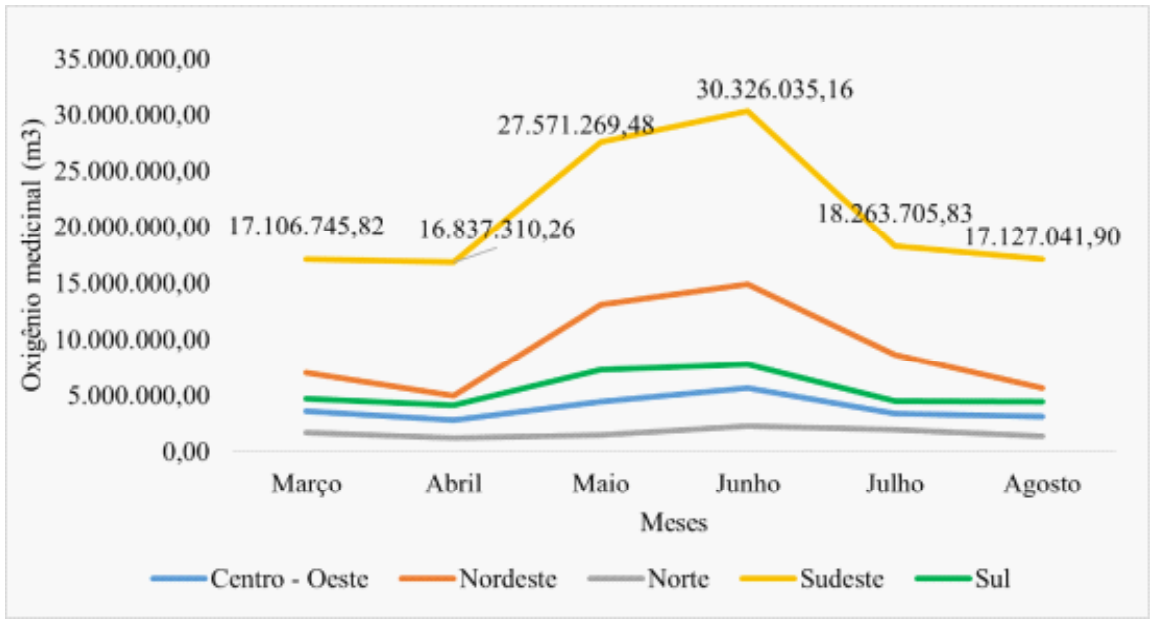

Figura 4. Venda de Oxigênio Medicinal Não Envasado no Brasil $\left(\mathrm{m}^{3}\right)$.

Fonte: Adaptado de ANVISA (2021f).

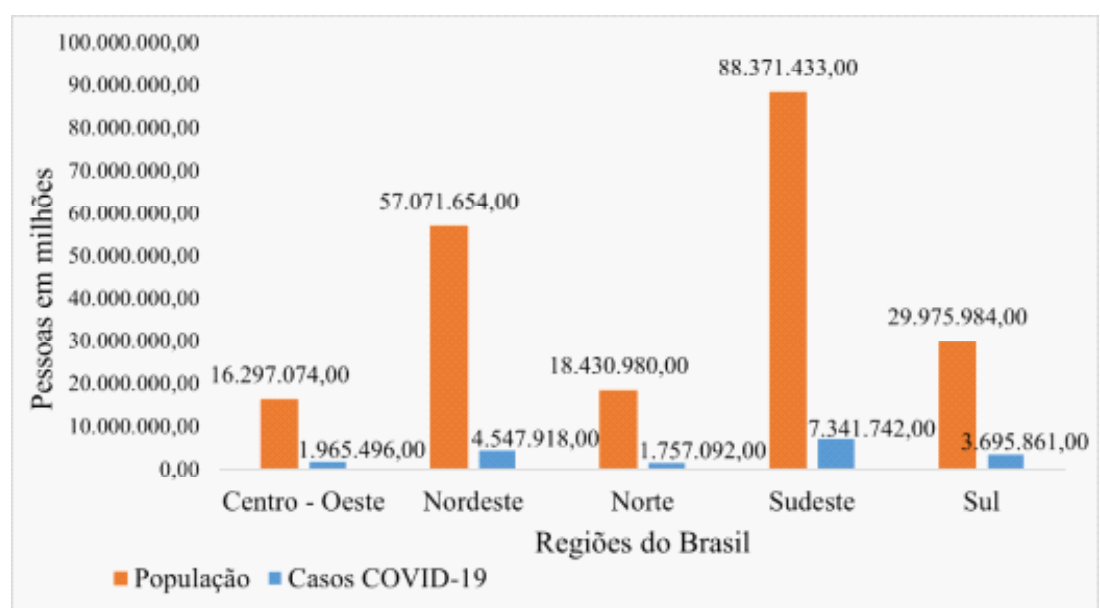

Figura 5. População das regiões brasileiras e casos da doença COVID-19 confirmados até a data de 17 de Julho de 2021.

Fonte: Adaptado de MS (2021b). 
Janeiro, na cidade de Vassouras, o hospital universitário é referência hospitalar de média e alta complexidade da Região Centro-sul Fluminense. Segundo o Ministério da Saúde (MS, 2021c), o hospital na competência do mês de agosto de 2021 possuía 64 leitos existentes de Unidade de Terapia Intensiva (UTI) II Adulto, voltados para o tratamento de pacientes com COVID-19 que apresentaram a Síndrome Respiratória Aguda Grave (SRAG).

A orientação para cuidados de pacientes com a condição clínica de SRAG é a imediata administração da oxigenoterapia suplementar (MS, 2020b), posto isso, constata-se que o surgimento de casos da doença influenciou o consumo de oxigênio no hospital.

O ano de 2019 representa o período de prépandemia, ou seja, o período que antecede o surgimento da doença COVID-19. Neste ano, o consumo de oxigênio medicinal totalizou $148.465 \mathrm{~m}^{3}$, sendo o mês de dezembro o de maior consumo, com $17.381 \mathrm{~m}^{3}$ e o mês de Abril o de menor consumo com $8.903 \mathrm{~m}^{3}$.

Considerou-se os anos de 2020 e 2021 como o período de disseminação do vírus, onde no ano de 2020 consumiu-se no total $177.688 \mathrm{~m}^{3}$ de oxigênio medicinal e, os meses de menor e de maior utilização foram novembro (com $9.678 \mathrm{~m}^{3}$ ) e dezembro (com 25.047 $\mathrm{m}^{3}$ ), respectivamente. Comparando-se o consumo de oxigênio medicinal entre 2019 e 2020 observou-se o aumento do consumo a uma taxa de $19,68 \%$.

Ressalta-se que para o ano de 2021 contabilizouse os dados até o dia 19 de agosto. No referido período foram necessários $197.074 \mathrm{~m}^{3}$ de oxigênio medicinal para suprir a demanda e constata-se que o consumo nos 8 primeiros meses do ano de 2021 ultrapassou em $19.386 \mathrm{~m} 3$ o total utilizado durante todo o ano de
2020 verificando-se o aumento a uma taxa de 10,91\%. Em contrapartida, relacionando-se os anos de 2019 e 2021para efeito comparativo, observou-se que houve um acréscimo no consumo a uma taxa de $32,74 \%$. Os meses de menor e de maior consumo, até o momento da conclusão deste trabalho, são junho e março com 6.524 $\mathrm{m}^{3}$ e $44.380 \mathrm{~m}^{3}$, respectivamente.

A figura 6 ilustra o consumo de oxigênio medicinal do hospital, na sua forma líquida, entre os anos 2019,2020 e 2021 (até o mês de agosto).

O agravamento da situação do suprimento de oxigênio medicinal no Brasil chegou a níveis bastante críticos, uma vez que em alguns casos, principalmente o da cidade de Manaus - AM, o clímax da crise de abastecimento se deu no início do ano de 2021, apesar de que os sintomas da crise já tinham alto nível de percepção e se concretizariam sem que nenhuma providência antecipada fosse tomada.

Segundo a White Martins (2021), empresa responsável pelo fornecimento do produto a rede hospitalar do estado do Amazonas, no período que antecedeu a pandemia a planta industrial localizada na cidade de Manaus operava com $50 \%$ de sua capacidade total de $25 \mathrm{mil} \mathrm{m}^{3}$ diários, produzindo o suficiente para suprir a demanda diária de seus clientes que juntos totalizavam de 10 a $15 \mathrm{mil} \mathrm{m}^{3}$.

Com o agravamento da pandemia constatou-se que o consumo dos hospitais do munícipio de Manaus era maior que o dobro da média dos maiores hospitais do país. Comparando-se o consumo entre os meses de janeiro a março de 2020, o consumo diário totalizava $12.500 \mathrm{~m} 3$ e durante a primeira onda da pandemia o consumo atingiu $30 \mathrm{mil} \mathrm{m} 3$ por dia, diminuindo no segundo semestre de 2020 para $15.500 \mathrm{~m} 3$. Até 14 de

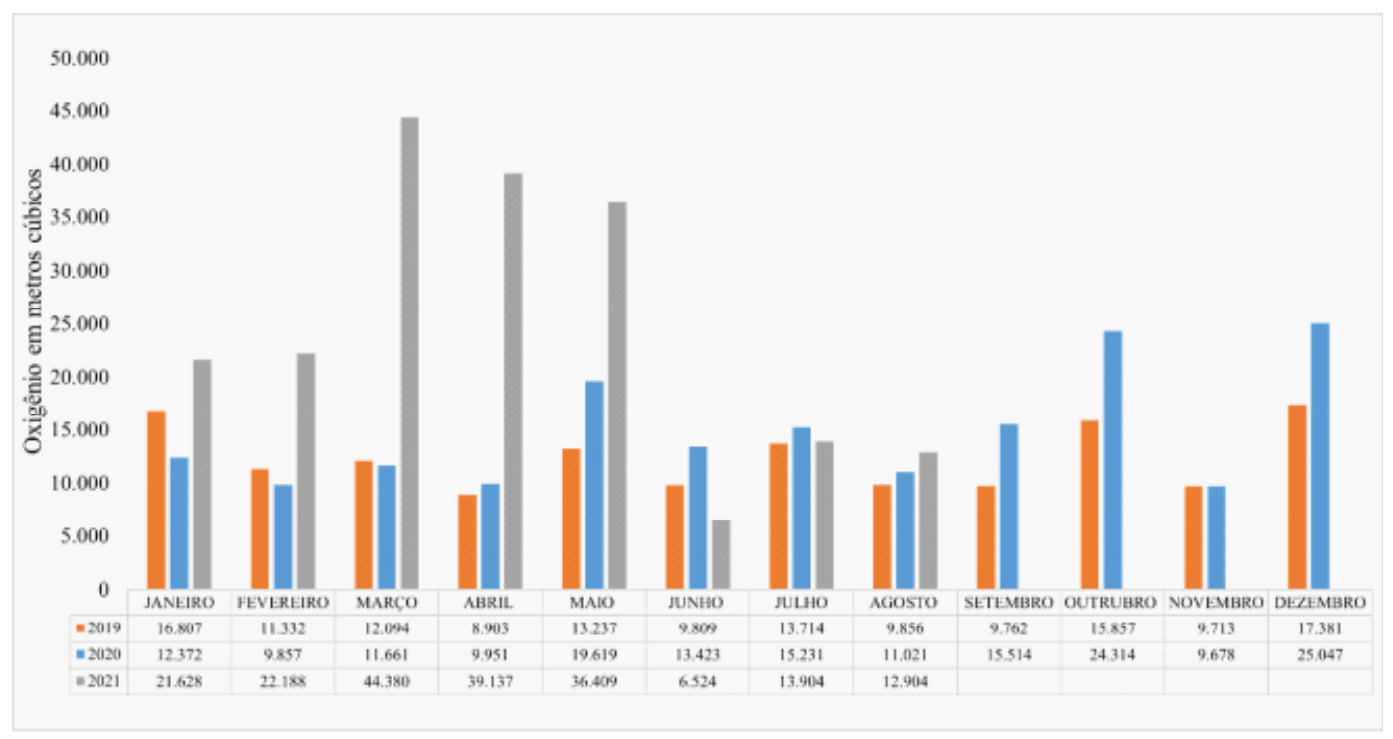

Figura 6. Consumo de oxigênio medicinal no hospital universitário de Vassouras. 
janeiro de 2021, a demanda atingiu cerca de 70 mil m3 diários com crescimento contínuo (White Martins, 2021).

Os fatores que contribuíram para o agravamento da crise sanitária foram o crescimento exponencial do consumo e o cenário logístico da região, onde é necessário utilizar vias alternativas a terrestre, como por exemplo as vias fluviais e aéreas para importar o produto (White Martins, 2021).

Como consequência da alta demanda provocada pelo aumento do número de casos da doença, Manaus enfrentou em janeiro de 2021, especificamente nos dias 14 e 15, o ápice da escassez do produto nos hospitais o que ocasionou a morte de pacientes devido a interrupção no fluxo de oxigênio $(\mathrm{G} 1,2021)$.

A crise sanitária decorrente da pandemia foi um evento que gerou grande impacto sobre a vida das pessoas em geral. Portanto, entende-se que a situação abre um espaço para trazer ao centro das discussões algumas questões importantes, tais como "o que podemos aprender sobre tudo que aconteceu?" e "como agir no sentido de que as consequências enfrentadas na crise não venham a se repetir com a mesma gravidade?"

Nesse sentido, uma das competências de gestão que pode contribuir positivamente para a sua melhoria é o amadurecimento e o aperfeiçoamento das organizações em gestão de riscos em processos. E a sugestão apresentada neste estudo consistiu em uma simulação de análise de riscos sobre os seus principais fatores geradores de riscos envolvidos e formas de gerenciá-los, por meio de uma matriz de probabilidade e impacto.

Matrizes de Probabilidade e Impacto são ferramentas aplicadas na classificação e priorização dos riscos com o intuito de gerenciá-los. Para estabelecer a classificação de prioridade de determinado risco, torna-se necessário considerar duas dimensões de risco, a probabilidade de ocorrência do risco e o impacto ocasionado caso o risco ocorra (PMI, 2017) .

Mediante a combinação dos diferentes graus de intensidade da probabilidade e do impacto tornase possível classificar cada risco em uma escala qualitativa utilizando-se definições de alto ( risco alto de ocorrência), médio (risco mediano de ocorrência) e baixo (risco baixo de ocorrência) (PMI, 2017).

Assim sendo, faz-se necessário descrições que relacionem a qualificação e as faixas de pontuações das duas dimensões de risco. O quadro 1 descreve a classificação da probabilidade de um risco se concretizar, com base no avanço da disseminação da COVID-19.

O quadro 2 mostra a descrição dos impactos em termos de número de casos de COVID-19 em relação à uma população regional, propostos para a matriz de risco desenvolvida.

Para esta simulação, foi desenvolvida uma matriz de probabilidade versus o impacto que permitiu a
Quadro 1. Classificação da probabilidade.

\begin{tabular}{|c|c|c|}
\hline \multicolumn{3}{|c|}{ DESCRIÇÃo DA PROBABILIDADE } \\
\hline Qualificação & Pontuação & PROBABILIDADE \\
\hline Alta & 0,5 & Provável que aconteça \\
Média & 0,3 & $\begin{array}{c}\text { Eventualmente pode acontecer } \\
\text { Pouco provável que aconteça }\end{array}$ \\
\hline
\end{tabular}

Fonte: Autores, 2021.

Quadro 2. Impacto em números proporcionais de casos de COVID1-19.

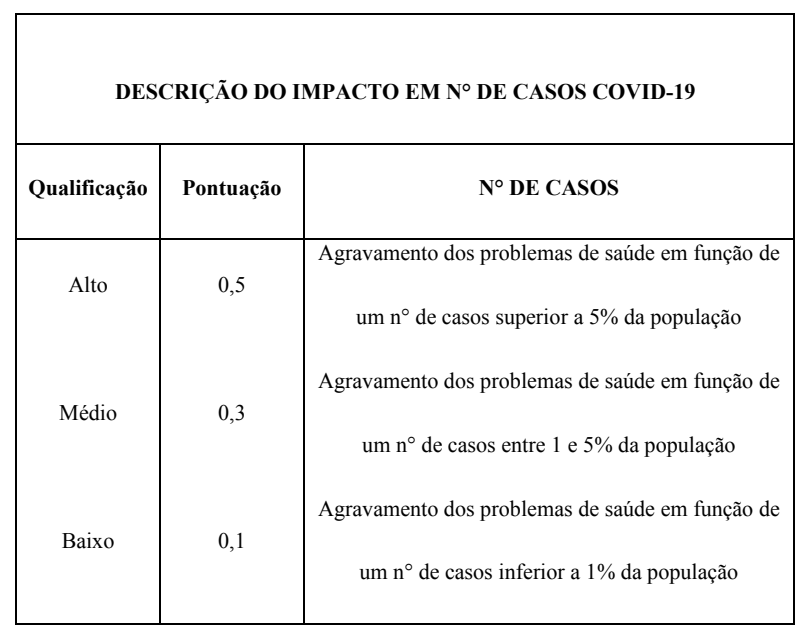

Fonte: Autores, 2021.

Tabela 1. Matriz de probabilidade e impacto (P x I).

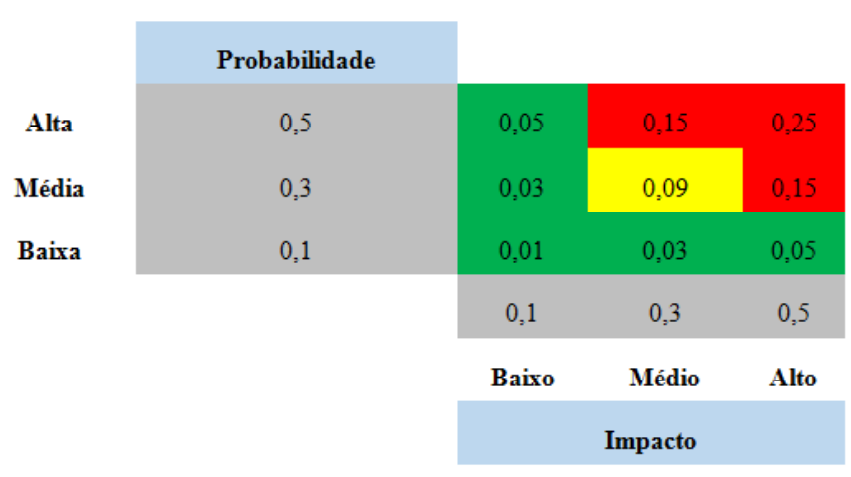

Fonte: Autores, 2021. 
Quadro 3. Registro de Riscos e Plano de Contingência de Risco.

\begin{tabular}{|c|c|c|c|c|c|c|c|c|c|}
\hline ID & Item de Risco & Título do Risco & $\begin{array}{l}\text { Probabilidade } \\
\text { (P) }\end{array}$ & $\begin{array}{c}\text { Impacto } \\
\text { (I) }\end{array}$ & $P \times I$ & Severidade & $\begin{array}{c}\text { Estratégia } \\
1 \text { - Evitar } \\
2 \text { - Mitigar } \\
3 \text { - Transferir }\end{array}$ & $\begin{array}{c}\text { Resposta ao Risco } \\
\text { (Ação) }\end{array}$ & $\begin{array}{c}\text { Responsável } \\
\text { pela Ação }\end{array}$ \\
\hline 1 & $\begin{array}{l}\text { Aumento } \\
\text { excessivo de } \\
\text { ocupação de } \\
\quad \text { leitos } \\
\text { hospitalares }\end{array}$ & $\begin{array}{c}\text { Como resultado da alta } \\
\text { transmissão da doença, pode } \\
\text { ocorrer aumento exagerado do } \\
\text { número de casos, resultando na } \\
\text { elevada taxa de ocupação de } \\
\text { leitos }\end{array}$ & 0,5 & 0,5 & 0,25 & Alta & 1 & \begin{tabular}{|} 
Intensificação de \\
campanhas de \\
conscientização e de \\
divulgação de práticas \\
individuais de \\
proteção contra a \\
doença \\
\end{tabular} & $\begin{array}{c}\text { Agente do } \\
\text { poder público }\end{array}$ \\
\hline 2 & $\begin{array}{c}\text { Escassez no } \\
\text { abastecimento } \\
\text { de oxigênio } \\
\text { medicinal }\end{array}$ & $\begin{array}{l}\text { Como resultado da alta ocupação } \\
\text { de leitos, pode ocorrer aumento } \\
\text { elevado de demanda de oxigênio, } \\
\text { resultando na escassez do produto } \\
\text { nas instalações hospitalares }\end{array}$ & 0,5 & 0,5 & 0,25 & Alta & 2 & $\begin{array}{l}\text { Adoção de medidas de } \\
\text { flexibilização de } \\
\text { critérios técnicos para } \\
\text { o fornecimento de } \\
\text { oxigênio }\end{array}$ & $\begin{array}{c}\text { Agente do } \\
\text { poder público }\end{array}$ \\
\hline 3 & $\begin{array}{l}\text { Piora da crise } \\
\text { de } \\
\text { abastecimento } \\
\text { de oxigênio } \\
\text { por parte das } \\
\text { empresas } \\
\text { fornecedoras }\end{array}$ & $\begin{array}{l}\text { Como resultado da flexibilização } \\
\text { dos critérios técnicos, pode } \\
\text { ocorrer baixa excessiva da } \\
\text { qualidade do oxigênio fornecido, } \\
\text { resultando na ineficácia do } \\
\text { tratamento de pacientes } \\
\text { internados. }\end{array}$ & 0,1 & 0,5 & 0,05 & Baixa & 3 & $\begin{array}{l}\text { As empresas deverão } \\
\text { aumentar os níveis de } \\
\text { inspeção e liberação } \\
\text { de oxigênio para } \\
\text { assegurar o novo } \\
\text { critério de qualidade } \\
\text { estabelecido }\end{array}$ & $\begin{array}{c}\text { Agente do } \\
\text { poder público }\end{array}$ \\
\hline 4 & \begin{tabular}{|} 
Redução súbita \\
da \\
disponibilidade \\
de oxigênio \\
medicinal em \\
estoque
\end{tabular} & $\begin{array}{l}\text { Como resultado da dificuldade de } \\
\text { logística de distribuição, pode } \\
\text { ocorrer um atraso no } \\
\text { fornecimento do produto, } \\
\text { resultando no nível crítico de } \\
\text { oxigênio disponivel em estoque. }\end{array}$ & 0,3 & 0,3 & 0,09 & Média & 2 & $\begin{array}{l}\text { Antecipar regulação } \\
\text { do estoque solicitando } \\
\text { oxigênio das regiões } \\
\text { com estoques mais } \\
\text { altos }\end{array}$ & $\begin{array}{c}\text { Agente do } \\
\text { poder público }\end{array}$ \\
\hline
\end{tabular}

Fonte: Autores, 2021.

elaboração de uma análise do ponto de vista qualitativo. A tabela 1 representa a matriz de probabilidade e impacto proposta por este trabalho.

Os níveis de severidade resultantes, para esta simulação seriam:

Severidade Alta (classificação vermelho): faixa superior a 0,09 ;

Severidade Média (classificação amarelo): faixa entre 0,05 e ,09;

Severidade Baixa (classificação verde): faixa entre 0,01 e 0,05 .

Uma vez elaborada uma lista de riscos, deve-se então realizar a priorização dos mesmos e classificálos quanto as faixas de pontuações dispostas nas descrições. Valendo-se de um plano de ação é possível estabelecer a severidade do risco, as estratégias a serem empregadas, as respostas aos riscos, bem como os responsáveis pelas ações de contingência. O Quadro 3 representa uma síntese desse processo, expondo uma análise consolidada de 4 itens de riscos, como forma de demonstração da prática.

A matriz de risco configura-se como uma ferramenta de gerenciamento que proporciona aos gestores uma visão geral sobre os riscos existentes e mediante ao grau de severidade auxilia na tomada de decisões e ações para que assim seja possível evitá-los, mitigá-los ou transferi-los de acordo com o grau de severidade de cada item de risco analisado.

\section{Considerações finais}

O processo de produção de gás oxigênio no Brasil consiste numa tecnologia bem conhecida e consolidada sem grandes alterações na planta industrial ao longo dos anos. Compreende basicamente operações que visam a purificação do ar e a posterior separação dos seus componentes em duas colunas de destilação, conhecidas comumente como um processo de retificação. Dessa forma, o processo é relativamente simples, consistindo na separação física de gases do ar atmosférico.

Mediante ao exposto ao longo do trabalho, foi perceptível que o gás oxigênio é de extrema importância para a área hospitalar e que, quando destinado para uso medicinal possui especificidades distintas em comparação com o que é destinado para a indústria em geral. Como observado, o oxigênio medicinal tem contato direto com o organismo humano e com isso, tornam-se necessárias medidas diferenciadas que garantam a qualidade para sua aplicação na área hospitalar.

Como evidenciado, em virtude da calamidade de saúde pública devido a COVID-19, o Hospital Universitário de Vassouras lidou com o agravamento 
da pandemia, influenciado pelo aumento da demanda de oxigênio. Não obstante, o problema foi refletido em praticamente toda a rede hospitalar do país, tendo como o auge a crise de falta de oxigênio na cidade de Manaus. Tal crise, mobilizou a Agência Nacional de Vigilância Sanitária que elaborou medidas para controlar a adversidade gerada, aumentar a produção de oxigênio pela indústria e consequentemente proporcionar uma maior disponibilidade do produto.

Amotivação deste trabalho surgiu após presenciar através dos canais de comunicação a dificuldade acarretada pelo momento e com isso, levantou-se o seguinte questionamento: "A crise poderia ser evitada com planejamento e gestão?". A resposta para essa questão estimulou a concepção de uma matriz de risco, onde o gestor tivesse acesso aos riscos possíveis de ocorrerem e seus eventuais impactos. Com tal ferramenta, seria possível desenvolver um processo de análise de riscos e consequentemente gerar um plano de resposta, visando o contingenciamento de eventos adversos futuros.

\section{Referências}

Agência nacional de vigilância sanitária - ANVISA (2021c). Agência disponibiliza painel para monitoramento de oxigênio medicinal. Brasília: ANVISA, 2021.Recuperado de: https://www.gov.br/anvisa/pt-br/assuntos/ noticias-anvisa/2021/agencia-disponibiliza-painel-para-monitoramento-deoxigenio-medicinal.

Agência nacional de vigilância sanitária - ANVISA (2021e) . Edital de Chamamento $\mathrm{N}^{\mathrm{o}} 5$ de 12 de Março de 2021. Brasília: ANVISA, 2021. Recuperado de: https:/www.in.gov.br/web/dou/-/edital-de-chamamento-n5-de-12-de-marco-de-2021-308249019.

Agência nacional de vigilância sanitária - ANVISA (2021d). Medidas da Anvisa aumentam capacidade de produção de oxigênio. Brasília: ANVISA, 2021. Recuperado de: https://www.gov.br/anvisa/pt-br/assuntos/noticiasanvisa/2021/medidas-da-anvisa-aumentam-capacidade-de-producao-deoxigenio.

Agência nacional de vigilância sanitária - ANVISA (2021a). Nota técnica $\mathrm{n}^{\circ} 20$ de 2021 e Processo n⿳0 25351.917591/2020-59. Recuperado de: https:// www.gov.br/anvisa/pt-br/assuntos/noticias-anvisa/2021/anvisa-liberaproducao-de-oxigenio-a-95-de-teor/nota-tecnica-o2-medicinal.pdf

Agência nacional de vigilância sanitária - ANVISA (2021b) . Resolução da Diretoria Colegiada N ${ }^{\circ} 461$ de 22 de janeiro de 2021. Brasília: ANVISA, 2021. Recuperado de: https://www.in.gov.br/en/web/dou/-/resolucao-rdc-n461-de-22-de-janeiro-de-2021-300303804.

Agência nacional de vigilância sanitária - ANVISA (2021c) . Resolução da Diretoria Colegiada No 482 de 19 de março de 2021.Brasília:ANVISA,2021. Recuperado de: https:/www.in.gov.br/en/web/dou/-/resolucao-rdc-n-482de-19-de-marco-de-2021-309557127.

Associação Brasileira da Indústria Química - ABIQUIM (2020). O desempenho da indústria química brasileira. Recuperado de: https://abiquimfiles.s3-us-west-2.amazonaws.com/uploads/guias_estudos/Livreto Enaiq 2020.pdf

Conselho Administrativo de Defesa Econômica - CADE (2018). Parecer 5/2018/CGAA4/SGA1/SG e Processo nº 08700.007777/2017-76.

Recuperado de: https://sei.cade.gov.br/sei/modulos/ pesquisa/md pesq documento consulta externa php? DZ2uWeaYicbuRZEFhBt - n3BfPLlu9u7akQAh8mpB9yPEWwTS vqPpD IO5JIHgQZ4IeeLPNKspeHt-ITzs2yXPg6PyNGwMq2vBY2e0uvL1rB92Oy9AhbYh\# ftn8.

Duarte, Clayton da Silva (2017). Análise de fornecimento de ar medicinal por meio da destilação criogênica em uma instituição hospitalar. Fortaleza: Dissertação (Graduação em Engenharia Mecânica) - Universidade Federal do Ceará, UFC. Recuperado de: http://www.repositorio.ufc.br/handle/ riufc/29275

G1, portal de notícias Globo (2021). Documentos mostram que mais de 30 morreram nos dois dias de colapso por falta de oxigênio em Manaus. Recuperado de: 25 https:/g1.globo.com/am/amazonas/noticia/2021/01/25/ documentosmostram-que-mais de-30-morreram-nos-dois-dias-de-colapsopor-faltade-oxigenio-em-manaus.ghtml .

Instituto Brasileiro de Geografia e Estatística - IBGE (2020) . Pesquisa Industrial Anual - Produto / Produção e vendas dos produtos e/ou serviços industriais, segundo as classes de atividades e os produtos. Recuperado de :https://sidra.ibge.gov.br/tabela/6705.

Mello, Luiz Carlos Brasil de Brito; Bandeira, Renata Albergaria de Mello; Leusin, Sérgio (2007) . Analisando uma proposta de alinhamento entre o suprimento e a demanda: o caso do setor de gases industriais no brasil. Revista Produção Online, Florianópolis. ISSN 16761901. Recuperado de: https://producaoonline.org.br/rpo/article/view/91.

Ministério da Saúde (2020a) . Brasil confirma o primeiro caso do novo coronavírus - Brasília, DF. Recuperado de : https://www.gov.br/pt-br/ noticias/saude-e-vigilancia-sanitaria/2020/02/brasil-confirma-primeirocaso-do-novo-coronavirus.

Ministério da Saúde - MS (2021c) . Cadastro de estabelecimentos de saúde - Brasília, DF. Recuperado de: http://cnes2.datasus.gov.br/Mod_Ind_Leitos Listar.asp?VCod Leito $=51 \&$ VTipo Leito $=3 \&$ VListar $=1 \&$ VEstado $=33 \& \bar{V}$ Mun $=330620 \&$ VComp $=202108$.

Ministério da Saúde - MS (2021b). Covid-19 no Brasil - Brasília, DF. Recuperado de: https://qsprod.saude.gov.br/extensions/covid-19_html/ covid-19_html.html

Ministério da Saúde (2021a). Orientações sobre a otimização do uso de oxigênio e suporte ventilatório em pacientes graves com COVID-19 Brasília, DF. Recuperado de :https://www.gov.br/saude/pt-br/coronavirus/ publicacoes-tecnicas/recomendacoes/orientacoes-sobre-otimizacao-do-usode-oxigenio-e-suporte-ventilatorio-em-pacientes-graves-com-covid-19.

Ministério da Saúde - MS (2020b). Protocolo de Manejo Clínico da COVID-19 na atenção especializada,1ª Edição editada, pág.16 - Brasília: DF. Recuperado de : https://bvsms.saude.gov.br/bvs/publicacoes/manejo_ clinico covid-19 atencao especializada.pdf.

Naik, Lakshmana (2015). A Review on Safety Operation Methods of a Cryogenic Air Separation Unit. international Journal of engineering technology, management and applied sciences.3.96-103.Recuperado de https://www.academia.edu/13643352/A_Review_on_Safety_Operation Methods of a Cryogenic Air Separation Unit.

Organização Mundial da Saúde - OMS (2019). Model List of Essential Medicines $-21^{\mathrm{a}}$ Edition. Geneva: World Health Organization. Recuperado de: https://apps.who.int/iris/bitstream/handle/10665/325771/WHOMVP EMP-IAU 2019.06-eng.pdf

Pachione, Renata (2003). Especialização é a tática da moda do setor. Química e Derivados online, v. 420. Recuperado de :https://www.quimica.com.br/ gases-industriais-especializacao-e-tatica-da-moda-setor/.

Project Management Institute - PMI (2017).Um Guia do Conhecimento em

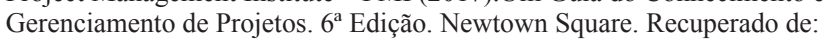
Guia-PMBOK 6ª-Edição.pdf (dicasliderancagp.com.br).

Shreve, R.N. \& Brink J.A (1997). Industria de Processos Químicos. 4 Edição. Editora Guanabara Koogan S.A.

Vieira, Fernanda Pires; Rediguieri, Camila Fracalossi; Rediguieri, Carolina Fracalossi (2013) . A regulação de medicamentos no Brasil. Porto Alegre: Artmed, 2013.

White Martins (2021). White Martins realiza operação de crise para enfrentar demanda sem precedentes de oxigênio no Amazonas Recuperado de: https://www.praxair.com.br/news/2021/white-martins-realiza-operacao-decrisepara-enfrentar-demanda-sem-precedentes-de-oxigenio-no-amazonas

Lubbe, A., \& Verpoorte, R. (2011). Cultivation of medicinal and aromatic plants for specialty industrial materials. Industrial Crops and Products, 34(1), $785-801$ 
Masotti, V., Juteau, F., Bessière, J. M., \& Viano, J. (2003). Seasonal and phenological variations of the essential oil from the narrow endemic species Artemisia molinieri and its biological activities. Journal of Agricultural and Food Chemistry, 51(24), 7115-7121.

Morais, L. A. S. (2009). Influência dos fatores abióticos na composição química dos óleos essenciais. Horticultura Brasileira, 27(2), S3299-S3302.

Németh, É., Bernáth, J., \& Héthelyi, É. (1993). Diversity in chemotype reaction affected by ontogenetical and ecological factors. In International Symposium on Medicinal and Aromatic Plants, 344, 178-187.

Olawore, N. O., Ogunwande, I. A., Ekundayo, O., \& Adeleke, K. A. (2005). Chemical composition of the leaf and fruit essential oils of Murraya paniculata (L.) Jack. (Syn. Murraya exotica Linn.). Flavour and Fragrance Journal, 20(1), 54-56.

Pichersky, E., \& Gang, D. (2000). Genetics and biochemistry of secondary metabolites in plants: an evolutionary perspective. Trends in Plant Science, 5(10), 439-445.

Ribeiro, S. M., Bonilla, O. H., \& Lucena, E. M. P. (2018). Influência da sazonalidade e do ciclo circadiano no rendimento e composição química dos óleos essenciais de Croton spp. da Caatinga. Iheringia, Série Botânica, 73(1), 31-38.

Santos, A. G. S. (2019). Controle de vetores em saúde ambiental: atividade larvicida de óleo essencial de Croton rhamnifolioides encapsulado em nanossistema polimérico frente ao mosquito Aedes aegypti. Dissertação de Mestrado em Gestão Ambiental, Instituto Federal de Educação, Ciência e Tecnologia de Pernambuco.

Shaalan, E. A. S., Canyon, D., Younes, M. W. F., Abdel-Wahab, H., \& Mansour, A. H. (2005). A review of botanical phytochemicals with mosquitocidal potential. Environment International, 31, 1149-1166.

Scherer, R., Wagner, R., Duarte, M. C. T., \& Godoy, H. T. (2009). Composição e atividades antioxidante e antimicrobiana dos óleos essenciais de cravo-daíndia, citronela e palmarosa. Revista Brasileira de Plantas Medicinais, 11, 442-449.

Souza, S., Meira, M., Figueiredo, L., \& Martins, E. (2010). Óleos essenciais: aspectos econômicos e sustentáveis. Enciclopédia Biosfera, 6(10).

Tellez, M. R., Khan, I. A., Kobaisy, M., Schrader, K. K., Dayan, F. E., \& Osbrink, W. (2002). Composition of the essential oil of Lepidium meyenii (Walp.). Phytochemistry, 61(2), 149-155.

Tiwary, M., Naik, S. N., Tewary, D. K., Mittal, P. K., \& Yadav, S. (2007). Chemical composition and larvicidal activities of the essential oil of Zanthoxylum armatum DC (Rutaceae) against three mosquito vectors. Journal of Vector Borne Diseases, 44(3), 198-204.

Unsicker, S. B., Kunert, G., \& Gershenzon, J. (2009). Protective perfumes: the role of vegetative volatiles in plant defense against herbivores. Current Opinion in Plant Biology, 12(4), 479-485. 